\title{
Contrapondo interpretações de agricultores e pesquisadores sobre possíveis problemas ambientais causados pelo cultivo de eucalipto
}

\section{Contrasting Interpretations of Peasants and Researchers about Possible Environmental Problems Caused by the Cultivation of Eucalyptus}

\author{
Silvia Lima de AQUINO*
}

\begin{abstract}
RESUMO
A atuação da indústria fabricante de celulose no Espírito Santo é acompanhada por diversos conflitos e protestos de lideranças comunitárias e sindicais, movimentos sociais, ONGs, etc., em virtude dos problemas sociais e ambientais que estes setores afirmam serem causados pela mesma desde que foi introduzida no Estado. Dentre estes problemas encontram-se, por exemplo, a expulsão de agricultores de base familiar e populações tradicionais, como grupos indígenas e quilombolas, de suas terras; alterações na disponibilidade de emprego no campo; destruição da Mata Atlântica; contaminação das águas de rios e córregos por agrotóxicos e dejetos industriais e homogeneização da paisagem. Diante disso, este trabalho tem o objetivo de estabelecer uma reflexão a respeito das percepções de agricultores de base familiar integrados à indústria de papel e celulose sobre as mudanças ocorridas no ambiente em que residem, vivem e trabalham, tendo em vista a expansão do cultivo de eucalipto para as atividades deste segmento.
\end{abstract}

Palavras-chave: agricultores de base familiar; eucalipto; impactos ambientais.

\begin{abstract}
The performance of industry cellulose producer in Espírito Santo is accompanied by many conflicts and protests from community leaders and trade unions, social movements, NGOs, etc. These sectors claim they are facing social and environmental problems caused by such industry since it was introduced in the state. Among these problems there are, for example, the expulsion of peasants and traditional peoples as indigenous and quilombolas of their lands, changes in job availability in the countryside; destruction of the Atlantic Forest; contamination of rivers and streams by pesticides and industrial waste and homogenization of landscape. Thus, this paper aims at reflecting on the perception of peasants integrated to cellulose and paper industry on the changes in the environment where they live and work, considering the expansion of eucalyptus cultivation to the activities of this segment.
\end{abstract}

Keywords: peasants; eucalyptus; environmental impacts.

\footnotetext{
" Doutora em Ciências Sociais em Desenvolvimento, Agricultura e Sociedade (UFRRJ). Analista em Reforma e Desenvolvimento Agrário do Instituto Nacional de Colonização e Reforma Agrária. E-mail: silvia.aquino@gmail.com
} 


\section{Introdução}

O monocultivo de eucalipto se disseminou de tal forma no território brasileiro que passou a ocupar o centro de uma infindável polêmica ambiental. Um dos segmentos responsáveis por esta disseminação é a indústria de papel e celulose, que encontrou nesse cultivo importante fonte de matéria-prima. Este artigo tem o intuito de analisar as interpretações de agricultores de base familiar ${ }^{1}$ sobre os possíveis impactos ambientais causados pela introdução da produção integrada de eucalipto, por uma grande indústria fabricante de celulose, na região em que vivem e trabalham, de modo a confrontá-las com os impactos identificados pela literatura científica sobre o tema. A fim de diferenciar as observações dos atores contrapostos nesta análise, chamaremos de "percepções" as observações dos agricultores a respeito das transformações no ambiente em que vivem e trabalham tendo em vista a introdução do fomento florestal, já que estas decorrem de suas experiências cotidianas e assistemáticas, e denominaremos de "impactos" aqueles definidos pelos pesquisadores, uma vez que estes decorrem de estudos científicos e sistemáticos sobre o tema.

Integração produtiva, produção integrada ou integração agroindustrial são denominações utilizadas para referir-se a um sistema de parceria assentado em um arranjo contratual estabelecido entre uma indústria (chamada de integradora) e o agricultor (chamado de integrado). Ao ingressar neste sistema, o agricultor integrado recebe da indústria insumos, assistência técnica, matrizes ou mudas e compromete-se ao fim da produção em comercializar, com exclusividade, o que foi produzido com esta indústria (ZIEBERT e SHIKIDA, 2004).

$\mathrm{O}$ artigo baseia-se em parte das informações colhidas por meio de um trabalho de campo destinado a fundamentar a tese de doutorado da autora. $\mathrm{O}$ trabalho de campo foi realizado no Espírito Santo, mais precisamente no município de Domingos Martins. Este município se localiza na macrorregião de planejamento metropolitana do Espírito Santo e, no que se refere à área de gestão administrativa, é classificado como pertencente à microrregião Sudoeste Serrana. Sua sede está situada a 542 metros de altitude e a uma distância de $43 \mathrm{~km}$ de Vitória, capital do Estado (IJSN, 2009).

Domingos Martins possui uma área de $1.225 \mathrm{~km}^{2}$, sendo que, aproximadamente, 26.346 hectares consistem em remanescentes de mata nativa (Atlântica). Ademais, é o $7^{\circ}$ município em extensão do Espírito Santo. O município é rico em fauna e flora e possui abundância de recursos hídricos, que são oriundos da bacia do Rio Jucu e seus afluentes, de onde derivam inúmeras cachoeiras (ALBEGARIA e LORETO, 2010). Domingos Martins divide-se em seis distritos: Sede, Aracê, Birricas, Isabel, Melgaço e Paraju e conta com uma população de 31.824 habitantes. Destes, aproximadamente $81 \%$ vivem no campo (IBGE Cidades, 2006) (IJSN, 2009)².

O município possui um relevo bastante acidentado e montanhoso, típico da região serrana do Estado ${ }^{3}$. Assim, conforme Nóbrega et al. (2008, p. 1), Domingos Martins possui “" [...] áreas significativas de 'terras frias', indicadas pelas altitudes entre 850 e 1.200 metros (60\% da área do município) e 'terras de temperaturas amenas', indicadas pelas altitudes entre 600 e 850 metros $(36 \%$ da área do município)". Estas condições geográficas atraem uma grande quantidade de turistas, que no inverno buscam Domingos Martins, que é dotado de inúmeras chácaras, pousadas sítios e hotéis, para a prática do turismo rural ${ }^{4}$.

No que diz respeito à distribuição da população ocupada, de acordo com os dados dos IJSN (2009), mais de $70 \%$ da população municipal está ocupada em atividades agropecuárias. Terra et al. (2010), apoiados em dados do IBGE (2006), asseveram que o total de propriedades

\footnotetext{
${ }^{1}$ Como no artigo não temos o objetivo de analisar ou discutir a identidade política relacionada a organizações de agricultores, e tendo em vista as indicações de Picolotto (2011), optamos por fazer uso dos termos agricultores de base familiar e agricultura de base familiar como denominação genérica para situações de trabalho e vida na agropecuária que estejam centradas na reprodução social da família.

${ }^{2}$ Disponível em: <http://www.ibge.gov.br/cidadesat/topwindow.htm?>.

${ }^{3}$ Região do Espírito Santo formada por terras altas, montanhosas e "frias", localizadas ao sul do Rio Doce.

${ }^{4}$ Ao falarmos em turismo rural, a partir de um entendimento mais abrangente, nos reportamos "[...] ao conjunto de modalidades e empreendimentos que têm lugar no espaço rural, tais como o agroturismo, o ecoturismo, o turismo cultural, o turismo esportivo, o turismo ecológico, os hotéis-fazenda, etc.". Neste sentido, estamos nos referindo a "[...] formas de organização econômica e produtivas que prestam serviços e/ou atividades de acolhimento, transporte, hospedagem, alimentação, lazer, recreação e entretenimento e outros [...]”, em áreas ou estabelecimentos rurais (SCHNEIDER, 2006, p. 1).
} 
agrícolas de Domingos Martins é de 4.753, onde cerca de $90 \%$ se caracteriza por possuir pequeno porte, com predomínio da agricultura de base familiar. Deste modo, seu coeficiente de Gini destaca-se entre os menores do Estado, girando em torno de 0,448 a 0,547 . As culturas de maior evidência no município são o café, a banana, o morango e olerícolas. Atualmente, em virtude da expansão do fomento florestal, a eucaliptocultura tem também se sobressaído, sendo as principais espécies de eucalipto cultivadas híbridos de Eucalyptus grandis e eucalipto urofila. No que se refere à produção animal, destacam-se granjas avícolas de médio e de pequeno portes.

A escolha do Espírito Santo como região de pesquisa deveu-se ao fato de que neste Estado está localizada a maior empresa fabricante de celulose de fibra curta (extraída do eucalipto) do mundo, a Fibria Celulose S/A. Esta empresa é resultante da fusão entre a Aracruz Celulose S/A. e a Votorantim C.P. Por sua vez, a seleção do município de Domingos Martins como locus do trabalho empírico, dentre outros fatores, foi motivada: 1) pelo fato de este município possuir o segundo maior número de contratos de fomento florestal do Espírito Santo, com 202 contratos, ficando neste quesito apenas atrás do município de Aracruz, onde se localiza uma das plantas industriais da empresa e onde se situava a sede da antiga Aracruz Celulose S/A.; 2) diferentemente de Aracruz - em que a produção agrícola fundamenta-se em atividades como a produção de cana-de-açúcar, criação de gado e, principalmente, o cultivo de eucalipto -, se consistir em um dos maiores produtores alimentos do Estado; e 3) ter, de acordo com dados do censo agropecuário de 2006 do IBGE, organizados pelo Instituto Jones dos Santos Neves (2009), mais de 70\% da população ocupada exercendo atividades que são realizadas no campo. Ou seja, a agricultura consiste em seu principal pilar econômico.

Ademais, como a região estudada é a que detém uma das maiores reservas de matas nativas do Estado e é reconhecida, justamente, pelas suas características ambientais, dentre as quais se encontram a declividade e a disponibilidade de águas em cachoeiras, nascentes, córregos e rios, entendemos que é importante discutirmos, mesmo que de forma breve, as possíveis alterações no ambiente local provocadas pelo cultivo de eucalipto.
As informações apresentadas neste artigo provêm de entrevistas semiestruturadas aplicadas a vinte agricultores de base familiar integrados e não integrados à indústria de papel e celulose, entre os meses de agosto e outubro de 2012. Entrevistamos também o coordenador de fomento florestal da Fibria Celulose S/A. no Espírito Santo, além de outros atores, cujas informações serão utilizadas na referida tese, a exemplo de representantes do Movimento dos Pequenos Agricultores - MPA - e do Instituto Capixaba de Pesquisa, Assistência Técnica e Extensão Rural - INCAPER.

A entrevista semiestruturada aproxima-se de uma conversa, todavia, direcionada para determinados temas. Neste sentido, é composta por um roteiro destinado a orientá-la, de modo que o entrevistado tem a possibilidade de discorrer sobre assuntos específicos (BONI e QUARESMA, 2005). Para Menezes (2002), esta estratégia é muito próxima da história oral e permite ao pesquisador o acesso a um depoimento primário envolvendo as visões dos entrevistados. Optamos pela aplicação de entrevistas semiestruturadas justamente porque permitem ao pesquisador a obtenção de informações detalhadas sobre determinado tema, por intermédio da perspectiva dos próprios entrevistados (MINAYO, 1996). Têm como vantagem a sua elasticidade quanto à duração. Proporcionam também uma cobertura mais profunda sobre o assunto em questão, além da interação direta entre entrevistado e entrevistador. Ademais, por meio da indução do ato de lembrar, permitem a abordagem de assuntos mais complexos, envolvendo arranjos afetivos e valorativos, fatores fundamentais para a categorização de significados pessoais de atitudes e comportamentos (BONI e QUARESMA, 2005).

No que se refere ao número ideal de entrevistas a serem realizadas, Duarte (2002) afirma que, em uma metodologia de base qualitativa, dificilmente o número de entrevistados pode ser definido a priori. Para o autor, a melhor estratégia é estabelecer a quantia necessária de entrevistados a partir das informações iniciais colhidas nas primeiras entrevistas. Assim, este número irá depender da qualidade das informações obtidas em cada depoimento, bem como da profundidade e do grau de recorrência e divergência destas informações. Neste sentido, salientamos que o número de entrevistas cujas informações extraídas subsidiaram o presente texto foi 
definido ao longo do trabalho de campo, tendo em vista a quantidade de informações obtidas e a partir do momento em que se percebeu que as mesmas começaram a se repetir com certa exaustão.

Como o trabalho de campo que abalizou este artigo foi realizado com o intuito maior, qual seja, o de fundamentar uma tese de doutorado, a opção por entrevistar agricultores integrados e não integrados baseou-se na necessidade de observar tanto os motivos que conduzem os agricultores a ingressarem no sistema de integração na produção de eucalipto quanto a resistirem a este sistema. Portanto, o debate sobre os possíveis impactos ao ambiente causados pela disseminação do eucalipto na região estudada consistiu em um dos muitos temas tratados nas entrevistas. Ademais, entendemos que mesmo os agricultores que não cultivam eucalipto são capazes também de observar as alterações no ambiente em que vivem e trabalham devido à expansão da atividade.

Dito isso, este trabalho divide-se em quatro partes, sendo a primeira esta introdução. Na segunda levantaremos alguns aspectos relacionados à implantação da produção integrada de eucalipto no Espírito Santo, conhecida como fomento florestal. Em seguida, apresentaremos alguns dos principais impactos causados pelo cultivo de eucalipto levantados por pesquisadores, de modo observar se os mesmos coincidem, se aproximam ou não das percepções dos agricultores a este respeito. Por fim, traçaremos algumas considerações finais.

\section{A introdução do cultivo eucalipto e da indústria de papel e celulose no Espirito Santo}

O Espírito Santo abrigou até 2009 a maior empresa produtora de celulose branqueada de fibra curta do mundo, a Aracruz Celulose S/A. (ANDRADE e DIAS, 2003). No referido ano, esta empresa teve suas ações incorporadas à Votorantim C.P., dando origem à Fibria Celulose S/A., que se manteve nesse posto. Dada a sua magnitude, desde a sua criação a Aracruz Celulose S/A. passou a demandar uma crescente quantidade de matéria-prima, por isso, até os dias de hoje a Fibria Celulose S/A. conserva no Espírito Santo e em outras regiões do país extensas plantações de eucalipto. Ao mesmo tempo, intensifica a criação de estratégias alternativas de expan- são do monocultivo de eucalipto, a fim de assegurar o suprimento de suas unidades fabris, difundindo, desta forma, o agronegócio da silvicultura.

Apesar da proeminência do monocultivo de eucalipto, a produção de café representou um dos setores mais importantes da economia do Espírito Santo até a década de 1960, quando a atividade atravessou uma crise nacional, cujos resultados repercutiram diretamente no Estado, culminando em um grande abalo em sua economia (DALCOMUNI, 1990). A crise provocada na atividade cafeeira, aliada aos anseios de setores políticos locais em promover o desenvolvimento econômico do Espírito Santo que, visivelmente, não acompanhava o desenvolvimento dos demais Estados da região sudeste, apontou para a necessidade da sua industrialização. Esta deveria ser acompanhada da tecnificação e diversificação da agricultura, que ainda era muito dependente da produção de café (LOUREIRO, 2006). A partir desta conjuntura, por intermédio dos Governos Federal e Estadual, no início dos anos 1970 - ápice da ditadura civil militar -, foram criados para o Espírito Santo complexos industriais, conhecidos na época como "Grandes Projetos Industriais", que deveriam movimentar a economia estadual (NADER, 2007). Dentre estes projetos encontrava-se a Aracruz Celulose S/A., criada em 1972 pela iniciativa privada, mas a partir de uma concentração de investimentos públicos estaduais e federais (AMBRÓZIO, 2005).

Cabe ressaltar, porém, que a introdução do cultivo de eucalipto no Espírito Santo antecedeu a criação da Aracruz Celulose S/A., mas desde seu início esteve vinculada à atividade industrial (LOUREIRO, 2006). Os primeiros plantios de eucalipto no Estado foram realizados em 1940 pela Companhia Ferro e Aço de Vitória - COFAVI, que com o plantio objetivava produzir seu próprio carvão, justamente no município de Aracruz, onde posteriormente foi implantada a fábrica homônima. Todavia, a Companhia nunca chegou a explorar de forma sistemática seus eucaliptais. Nos anos 1950, a Companhia Siderúrgica Vale do Rio Doce, cujo serviço florestal começou a funcionar em 1958, também efetuou plantios de eucalipto nos municípios de Baixo Guandu, Aracruz e Linhares para fabricar dormentes destinados à Estrada de Ferro Vitória a Minas, postes para sustentação de fios elétricos, telegráficos e telefônicos, construção civil e venda de excedentes. Além disso, também em Aracruz 
a Companhia comprou terras para introduzir plantios de eucalipto para o preparo de carvão vegetal (ECOTEC, 1967; HASSE, 2006).

Contudo, foi no final da década de 1960 que o Espírito Santo assistiu, de fato, à expansão do cultivo de eucalipto. Esta expansão foi impulsionada, por um lado, pela criação da Aracruz Florestal em 1967 por um grupo de empresários, membros da elite local, que, inicialmente, objetivavam exportar cavacos de madeira para o Japão. E, por outro, sobretudo, por uma articulação política destes empresários, sócios da Aracruz Florestal, reunidos por intermédio de uma empresa de consultoria chamada Economia e Engenharia S/A. ECOTEC (HASSE, 2006; VINHA, 1999). Desde os anos 1950 a ECOTEC atuava na elaboração de estudos técnicos para a realização de projetos de infraestrutura, tanto para o governo estadual quanto para a Companhia Vale do Rio Doce.

As notícias de que os mercados internacionais de madeira estavam abrindo novas oportunidades locacionais motivaram a intermediação de interesses no Brasil destes empresários (reunidos pela ECOTEC) pelos governos militares (FASE, 2002). Aproveitando-se do momento político e econômico estadual (de crise da atividade cafeeira e início da industrialização e modernização da agricultura) e federal (em virtude dos incentivos fiscais destinados ao monocultivo de árvores exóticas), além do trânsito que tinham nessas esferas, estes empresários conseguiram colocar a criação de uma indústria de papel e celulose como um dos grandes projetos industriais pensados para o Espírito Santo.

O pontapé inicial para a expansão dos plantios de eucalipto e, por conseguinte, para a introdução da indústria de papel e celulose no Estado se deu em 1966, com a realização de um levantamento inicial pela ECOTEC sobre o mercado de celulose, com vistas a estruturar uma empresa no ramo (FASE, 2002). O estudo detectava um quadro de estagnação na fabricação mundial de celulose, decorrente da insuficiência de madeira, cuja produção não acompanhava o crescimento da demanda da indústria (LOUREIRO, 2006). A ECOTEC indicou o município de Aracruz como o ideal para o início dos plantios de eucalipto e, em seguida, para implantação da indústria, devido às condições climáticas e de solo adequadas, topografia plana favorável à mecanização, além da localização, próxima a Vitória e também perto do mar, o que facilitava a construção de um porto no futuro para o escoamento da produção e exportação do produto.

Os empresários articularam formas de financiamento via incentivos fiscais para a aquisição de terras e fundaram em 1967 a Aracruz Florestal. Receberam do governo estadual os dez mil hectares anteriormente explorados pela COFAVI e lá iniciaram os primeiros plantios de eucalipto (FASE, 2002). Após a definição do local de instalação da empresa, os empresários começaram a adquirir terras no município de Aracruz e expandiram-se para os municípios vizinhos, Conceição da Barra e São Mateus. Em 1969, foram iniciados os estudos de viabilização da implantação de uma fábrica de celulose. Estes estudos foram concluídos em 1971, tendo comprovado a viabilidade do projeto de produção de celulose. Para tanto, colocavam a necessidade de reestruturação do projeto florestal estabelecido inicialmente, a fim de melhor atender ao projeto industrial (LOUREIRO, 2006).

Diante disso, em 1972 foi fundada a Aracruz Celulose S/A. - a Aracruz Florestal criada anteriormente foi transformada em sua subsidiária - a partir da reunião de vários grupos acionistas: BNDE (25,90\%), Cia. Souza Cruz Indústria e Comércio (25,29\%), FIBASE (14,72\%), Grupo Billerud (6,07\%), Grupo Lorentzen (5,08\%), Vera Cruz Agroflorestal S/A. (3,37\%), Grupo Moreira Salles $(2,63 \%)$ e os restantes 391 acionistas, como o Grupo Oliver Araújo, CBPO, Paranapanema S/A., Refinaria União e outros (FERREIRA, 2002). Em 1975, o grupo conseguiu financiamento do BNDE para implantação de seu projeto. Com isso, em 1978, em Barra do Riacho, distrito pertencente ao município de Aracruz, foi inaugurada a primeira fábrica da Aracruz Celulose S/A., conhecida como "A" (ANDRADE e DIAS, 2003). Em 1991, foi criada a Fábrica "B" e, em 2002, a Fábrica "C", localizadas também em Barra do Riacho (DE’NADAI et al., 2005).

Desse modo, em pouco tempo a Aracruz S/A. se tornou um grande complexo, maior produtor de polpa branqueada de celulose de eucalipto no mundo e uma das maiores proprietárias de terra no Espírito Santo. Segundo Dalcomuni (1990), em 1987 o Grupo Aracruz detinha sob sua propriedade mais de 100.000 ha de terras agricultáveis no Estado, sendo 41.000 ha localizados no 
município de Aracruz e 59.000 ha nos municípios de Conceição da Barra e São Mateus. Além disso, a autora acrescenta que, considerando ainda as áreas planas do Estado, que são de 1.505.000 hectares, e, destes, 973.000 hectares sendo áreas planas mecanizáveis, a Aracruz Celulose S/A. ocupava com suas plantações $8,75 \%$ da área.

De acordo com informações corporativas da Aracruz Celulose S/A. do ano de 2001, apresentadas por Ferreira (2002), em 1999, em Aracruz, por exemplo, a empresa era proprietária de cerca de $41 \%$ das terras do município. Já no município de Conceição da Barra, cerca de $68 \%$ do território era ocupado pelo plantio de eucalipto da empresa. Ademais, conforme dados do INCRA de 2001, apresentados pela FASE (2002), os municípios de Aracruz, São Mateus e Conceição da Barra concentravam no período de publicação dos dados 79.075 hectares de eucalipto, correspondendo a $62 \%$ da área total da empresa no Estado.

Este movimento de concentração fundiária estabelecido pela empresa foi acompanhado por diversos conflitos com populações locais tradicionais (DALCOMUNI, 1990). Isto porque, para reunir terras para a introdução do monocultivo de eucalipto e instalação de suas indústrias, a Aracruz Celulose S/A. se valeu inclusive de processos violentos e ilícitos. Em Aracruz, por exemplo, a empresa ocupou terras pertencentes aos indígenas das etnias Tupiniquim e Guarani Mbya. Em Conceição da Barra e São Mateus, a empresa se apropriou do território de populações remanescentes de quilombos. ${ }^{5}$ Além de conservar no Espírito Santo e em outras regiões do país extensas plantações de eucalipto, a Aracruz Celulose $\mathrm{S} / \mathrm{A}$., a fim de assegurar o fornecimento de matéria-prima para a sua indústria, investiu em estratégias alternativas de expansão do monocultivo de eucalipto, sendo uma delas a introdução de um modelo de integração entre agricultores e indústria, chamado de fomento florestal (ANDRADE e DIAS, 2003).

Cabe ressaltar que, no final do ano de 2009, a Aracruz Celulose S/A. - que na época possuía aproximadamente 154.000 hectares de terras no Espírito
Santo e sozinha já era a maior produtora mundial de celulose branqueada de eucalipto, abastecendo $24 \%$ do mercado desse produto - teve suas ações incorporadas à Votorantim Celulose e Papel, dando origem a uma nova empresa denominada Fibria Celulose S/A. Desta maneira, a planta industrial localizada em Aracruz tornou-se uma das unidades desta empresa. Apesar desta junção, em função da marca ser consolidada internacionalmente, o nome Aracruz foi mantido pela Fibria Celulose S/A. na unidade de Barra do Riacho, que passou a se chamar Fibria Aracruz. ${ }^{6}$

\section{A definição de integração produtiva e a organização do programa de fomento florestal}

Produção integrada, integração produtiva ou integração agroindustrial são termos, comumente, utilizados para nomear um sistema baseado em um contrato de parceria entre agricultores e uma agroindústria processadora. Por meio dessa relação contratual, os agricultores se comprometem em produzir determinada matéria-prima que, por sua vez, será adquirida e beneficiada pela agroindústria (PAYÉS, 1993). No Brasil, o sistema de integração produtiva é utilizado por grandes agroindústrias processadoras, sobretudo a partir dos anos 1960, e é aplicado em diversos ramos, como na produção de suínos e aves, tabaco, flores, frutas, dentre outros. Entretanto, a partir do final da década de 1980 e, principalmente, nos anos 1990, indústrias dependentes de madeira proveniente, nomeadamente, de espécies exóticas como o eucalipto, a exemplo das siderúrgicas e fabricantes de papel e celulose, passaram a utilizar este sistema, que neste caso específico é também conhecido como fomento florestal e os agricultores integrados como fomentados.

O fomento florestal é um modelo de produção integrada que funciona por meio de um contrato de "parceria" entre empresas dependentes de madeira e agricultores. Embora não possua apenas um único modelo, assim como em outros sistemas de integração

\footnotetext{
${ }^{5}$ Por questão de tempo, espaço e em virtude do tema não fazer parte do objetivo deste artigo, não poderemos nos adentrar ao debate a respeito dos conflitos entre populações tradicionais e a indústria fabricante de celulose no Espírito Santo. Todavia, há uma série de trabalhos que se ocupam do tema, a exemplo de Ferreira (2002) e Loureiro (2006).

${ }^{6}$ Disponível em: <http://www.prodfor.com.br/mantenedoras/item/54-aracruz-celulose-sa $>$.
} 
entre agricultores e indústrias, os programas de fomento florestal, em geral, funcionam da seguinte maneira: a indústria integradora fornece ao integrado mudas, insumos e assistência técnica. O indivíduo, ao assinar o contrato de integração, recebe esses recursos e assume a responsabilidade de produzir a madeira que será comprada pela indústria. Caso o integrado não venda a produção para a indústria, deve pagar os recursos que recebeu da mesma (SOARES et al.,2010).

A integração entre agricultores e indústria começou a ser adotada pelas indústrias que dependem de recursos florestais a partir da década de 1980. Este momento coincide com o fim da política de incentivos fiscais do governo brasileiro para a silvicultura implementados desde os anos 1950, que ocorreu na prática em 1986 e oficialmente em 1988, em virtude, dentre outros fatores, da crise econômica que ocorreu no país nos anos 1980 (GONÇALVES, 2006); (FAO, 2004). ${ }^{7}$

Apesar de ter seu início nos anos 1980, foi a partir da década de 1990 que o fomento florestal passou figurar de forma mais incisiva no repertório de estratégias das empresas dependentes de matéria-prima oriunda da silvicultura no Brasil, para garantir e/ou complementar o abastecimento de suas plantas industriais. A partir desse momento, estas empresas se conscientizaram de que o governo federal não retomaria a política de incentivos fiscais para o setor (FAO, 2004; GONÇALVES, 2006). Acserald (2007) assevera que, além do fim dos incentivos fiscais, contribuíram para esta situação mais dois elementos: uma crise atravessada pelo mercado mundial de celulose, que enfrentou graves quedas em seus preços em 1990, acirrando ainda mais a concorrência por mercados, e a emergência, neste mesmo período, de intensas manifestações oriundas da sociedade civil, movimentos sociais, ONGs, que se colocaram contra a expansão do monocultivo de eucalipto em diversas áreas do Brasil.
A produção integrada de eucalipto foi introduzida no Espírito Santo pela Aracruz Celulose S/A. nos anos 1990 (ANTOGIOVANNI, 2006). Inicialmente, o programa de integração introduzido por esta empresa era chamado apenas de fomento florestal, mas, em uma estratégia de divulgação utilizada pela empresa, a partir de 2004 o mesmo passou a ser chamado de "Programa Produtor Florestal". ${ }^{8}$ Este programa foi mantido pela Fibria Celulose S/A. que, ao se constituir, promoveu a revisão e a unificação dos programas no Espírito Santo e na Bahia, retomou a contratação de aproximadamente 10 mil hectares de plantios com integrados e passou a denominá-lo de Programa Produtor Florestal da Unidade Aracruz.

Para entender melhor como o programa de fomento florestal foi organizado inicialmente pela Aracruz Celulose S/A., é interessante analisarmos alguns de seus documentos utilizados para divulgação do programa. Um deles trata-se de um folder publicado em dezembro de 2007, em que a referida empresa afirma que o Programa Produtor Florestal:

[...] Consiste em uma parceria formada entre empresa e o produtor rural, sustentada por um contrato de compra e venda de madeira, no qual a empresa se compromete a comprar a produção do primeiro ciclo de 6 anos da cultura [de eucalipto] e o produtor, a vendê-la.

Em uma revista intitulada Programa de Fomento Florestal da Aracruz Celulose, publicada em agosto do ano de 2003 pela empresa, há uma explicação mais detalhada de como funciona o fomento florestal:

Por contrato, o Fomento Florestal garante a compra de toda a madeira produzida, se compromete a fornecer recursos operacionais (mudas, adubo, isca, calcário,

\footnotetext{
${ }^{7}$ Dentre os referidos incentivos, encontram-se: os incentivos destinados à indústria fabricante de papel e celulose concedidos pelo governo federal na década de 1950, por meio do Plano de Metas - a partir do estabelecimento de medidas tarifárias e de concessão de financiamentos, majoritariamente, por intermédio do Banco Nacional de Desenvolvimento Econômico-BNDE - e, principalmente, as diversas políticas públicas de cunho financeiro, institucional e creditício que tiveram início a partir de meados da década de 1960 e se intensificam na década 1970. Dentre estas políticas destacam-se: a) Código Florestal de 1965, que estabeleceu as diretrizes para a concessão de incentivos aos setores que investissem no monocultivo de árvores exóticas destinadas ao segmento industrial; b) a Lei n. ${ }^{\circ} 5.106$, de 2 de setembro de 1966, que regulamentou os incentivos fiscais previstos pelo referido Código; 3) a criação do Fundo de Investimentos Setoriais - florestamento/ reflorestamento - em 1974; 4) e a implementação do I e II Programas Nacionais de Papel e Celulose, em 1967 e 1987, respectivamente.

8 "A exemplo da revista Produtor Florestal, o programa de fomento da Aracruz Celulose passou a se chamar Programa Produtor Florestal. A empresa optou pela mudança por acreditar que a nova denominação traduz melhor o perfil do projeto, que tem como parceiro principal o homem do campo. Portanto, a partir de agora, desde os técnicos até as publicações referentes ao programa passarão a tratá-lo como Programa Produtor Florestal" [grifo nosso] (ARACRUZ, 2004, p. 1).
} 
formicida) e assistência técnica, além de recursos financeiros destinados a custear a implantação e manutenção dos plantios. Os recursos financeiros são convertidos em metros de madeira (equivalência ao produto), que serão ressarcidos pelo produtor por ocasião do corte e venda da madeira à empresa. Dessa forma, o débito do participante com a empresa é em madeira, e não em dinheiro. O recurso adiantado pela Aracruz Celulose corresponde a, aproximadamente, $20 \%$ da produção total prevista. Os recursos operacionais e a assistência técnica são bonificados ao produtor quando cumprido o contrato (ARACRUZ, 2003, p. 3).

Desta forma, o produtor integrado é o responsável pelo plantio, manutenção, colheita e transporte da madeira até um dos depósitos do fomento, distribuídos por vários municípios do Espírito Santo, sul da Bahia e na região de Conselheiro Pena, em Minas Gerais, e pode reter até 3,5\% da produção para seu consumo. A madeira produzida deve obedecer aos padrões de qualidade definidos pela empresa. Para tanto, esta possui um serviço de supervisão dos plantios e assistência técnica, que são realizados por uma equipe de técnicos que se dividem entre os segmentos de silvicultura e colheita para atender aos fomentados. São os técnicos os responsáveis pela ligação entre empresa e integrados. O preço pago pela madeira produzida pelos integrados é definido pela tabela de compra da empresa que, por sua vez, é fundamentada nas variações do IGP-M (ARACRUZ, 2003).

Segundo informações contidas no Novo Plano Estratégico de Desenvolvimento da Agricultura Capixaba - 2007-2025, elaborado por Galvêas e Dadalto (2007), o Estado do Espírito Santo controla e atua no programa de fomento florestal privado por meio de duas ações para promover o licenciamento. A primeira é uma vistoria realizada pelos técnicos do Instituto de Defesa Agropecuária e Florestal - IDAF - circunscritos à área do projeto a ser implantado. Esta vistoria ocorre quando o produtor solicita o fomento, sendo o seu objetivo determinar se na área é possível fazer o plantio. Se a área for liberada, o contrato entre o produtor e a empresa é firmado. A segunda ação de controle do Governo é a auditoria aos projetos. Esta auditoria é realizada anualmente, pelos técnicos do IDAF pertencentes ao escritório central. No evento, são avaliados todos os quesitos florestais e ambientais decorrentes do plantio de eucalipto, sendo que, se forem constatadas irregularidades, estas são encaminhadas por meio de notificação à Fibria Celulose $\mathrm{S} / \mathrm{A}$. que, por sua vez, deve em prazo estipulado informar os procedimentos adotados e suas justificativas. ${ }^{9}$

$\mathrm{O}$ coordenador de fomento florestal da Fibria Celulose S/A. no Espírito Santo, em entrevista concedida em 2012, explica que a área exigida para ingressar no programa vai "de dois hectares até os de mil, não tem limite superior". E acrescenta que no Espírito Santo, atualmente, há 2.500 contratos de fomento florestal e entre $20 \%$ e $30 \%$ dos agricultores integrados à empresa possuem menos de 10 hectares de terra. Em sua opinião, esse perfil deve-se, principalmente, à estrutura fundiária do Estado, menos concentrada. Deste modo, são poucos os grandes proprietários que participam do programa no Espírito Santo, sendo a média da propriedade dos agricultores capixabas integrados de 16 ha (Coordenador de Fomento Florestal da Fibria, 2012).

[...]. No Espírito Santo nós temos entre 20 e $30 \%$ abaixo de 10 hectares. Depois você tem uma grande faixa aí até os 100 ha. Depois a gente tem pouquíssimos, não deve chegar a 20 produtores - hoje nós temos 2.500 contratos - 20 contratos acima de 100 ha aqui. Na Bahia o perfil é diferente, por causa do perfil fundiário da terra aqui, a terra aqui é menos concentrada. A média dos contratos no Espírito Santo no momento é de 16 hectares, você pega o Espírito Santo inteiro, 16 ha (Coordenador de Fomento Florestal da Fibria, 2012).

Canto et al. (2009), por meio de uma pesquisa desenvolvida em cinco regiões do Espírito Santo ${ }^{10}$,

\footnotetext{
${ }^{9}$ A Secretaria de Estado do Meio Ambiente do Espírito Santo (SEMA/ES), por meio do Instituto de Defesa Agropecuária e Florestal do Estado do Espírito Santo (IDAF/ES), estabelece que até $40 \%$ da área plana da propriedade pode ser plantada com árvores de acordo com o programa de fomento e, quando a área encontra-se em declive até $56 \%$ de sua extensão, podem ser utilizados para o plantio de eucalipto (KENGEN, 2002).

${ }^{10}$ De acordo com Canto et al. (2009, p. 124), foram pesquisadas as seguintes regiões e municípios: I) Região de Colatina: Águia Branca, Alto Rio Novo, Baixo Guandu, Colatina, Mantenópolis, Pancas e São Domingos do Norte; II) Região de Marechal Floriano: Alfredo Chaves, Conceição do Castelo, Domingos Martins e Marechal Floriano; III) Região de Conceição da Barra: Boa Esperança, Conceição da Barra, Pinheiros e São Mateus; IV) Região de Aracruz: Aracruz, Ibiraçu, Linhares e Rio Bananal; e V) Região de Santa Teresa: Itaguaçu, Santa Maria de Jetibá e Santa Teresa.
} 
com a aplicação de questionários a 71 integrados, cujos contratos de fomento florestal foram finalizados entre outubro de 2004 e outubro de 2005 , observam que $80,8 \%$ dos contratos eram desenvolvidos em áreas de até 30 ha. Conforme os autores: "A área fomentada por contrato variou entre 1,5 e 100,0 ha, sendo de até 30 ha em $84,8 \%$ dos casos" (CANTO et al., 2009, p. 123). O Plano de Manejo Florestal do Espírito Santo e Bahia, publicado pela Fibria Celulose S/A. em 2010, destaca a dimensão e o papel do fomento florestal para as unidades fabris da empresa localizadas no Espírito Santo, uma vez que afirma que o programa de fomento florestal dirigido pela Unidade Aracruz na época de sua publicação abrangia:

Cerca de 3.300 contratos e alcança[va] mais de 131 municípios, sendo 70 do Espírito Santo, 37 de Minas Gerais, 12 da Bahia e 12 do Rio de Janeiro. Conta com cerca de 85.750 hectares contratados, dos quais quase 83 mil hectares já plantados com eucalipto (FIBRIA, 2010, p. 20).

\section{Agricultores versus pesquisadores: contrapondo interpretações sobre possíveis problemas ambientais causados pelo cultivo de eucalipto}

A palavra eucalipto tem sua origem na língua grega, significando "verdadeira cobertura". Dentro desta denominação, encontramos várias espécies de vegetais do gênero Eucalyptus (VITAL, 2007). De acordo com Pryor (1971), a classificação do gênero Eucalyptus é relativamente complicada, na medida em que envolve um grande número de espécies - de 400 a 700, dependendo de como são consideradas. Todavia, a autora explica que as espécies de interesse para o Brasil se distribuem na costa Leste e nas ilhas ao Norte da Austrália. Conforme a autora, nessas áreas existem mais ou menos 200 espécies, das quais só algumas são de interesse comercial.

Em se tratando de uma planta exótica, segundo Viana (2004), há dificuldades para estabelecermos com exatidão o período em que as primeiras mudas de euca- lipto foram introduzidas no Brasil. Para tentar esclarecer tal informação, este autor busca respaldo no trabalho de Armando Navarro Sampaio, chamado Eucaliptos para o Brasil, publicado em 1957, na Revista Arquivos do Serviço Florestal. Nesta publicação, este autor afirma, de acordo com os dados disponíveis na época, que, inicialmente, acreditava-se que as primeiras mudas de eucalipto tinham sido introduzidas no Brasil em 1868 no Rio Grande do Sul e nesse mesmo ano na Quinta da Boa Vista, no Rio de Janeiro. Entretanto, ao pesquisar um pouco mais sobre a história desta planta no país, Sampaio se deparou com informações de que em São Paulo ocorreram plantios antes deste período, mais precisamente entre 1861 e 1863, e que antes disso, aproximadamente entre 1824 e 1829, foram plantadas mudas dessa espécie no Jardim Botânico, no Rio de Janeiro, na gestão do Frei Leandro como diretor do parque. ${ }^{11}$

A despeito destas informações, Viana (2004) destaca que até o início do século XX o eucalipto era plantado no Brasil apenas como um elemento decorativo, como quebra-vento, ou pelas suas propriedades sanitárias e pelo seu aroma característico. É somente nos anos 1950 que o eucalipto passou a ser visto também em virtude de sua função econômica, momento em que se cogitava sua utilização para a confecção de celulose e chapas. No entanto, o cultivo de eucalipto para fins econômicos só começou a ser realizado de forma mais efetiva no Brasil nos anos 1960, quando foi "sancionada a Lei n. ${ }^{\circ} 5.106$, de 1966, com os incentivos fiscais recolhidos ao Fundo de Investimento Setorial - FISET Reflorestamento - e aplicados mediante a aprovação de projetos apresentados ao então Instituto Brasileiro de Desenvolvimento Florestal - IBDF" (VIANA, 2004, p. 4).

Foi exatamente neste período, mais precisamente no ano de 1967, que, como vimos anteriormente, os plantios de eucalipto em larga escala para fins comerciais, especialmente relacionados ao setor de papel e celulose, foram introduzidos no Espírito Santo, antecedendo à criação da Aracruz Celulose S/A., em 1972. Como sabemos, a referida empresa foi criada no âmbito dos grandes projetos industriais desenvolvidos com o intuito

\footnotetext{
${ }^{11}$ Frei Leandro foi um "frade carmelita que integrava as Academias de Ciências de Londres e Munique, professor de Botânica da Academia de Medicina e Cirurgia do Rio de Janeiro [...] foi o primeiro diretor botânico do Jardim na época do primeiro Reinado. Na sua gestão, o Jardim Botânico adquire o caráter científico, mais tarde sedimentado por Barbosa Rodrigues [...]." Informação disponível em: <http://www.jbrj.gov.br/historic/fr_leand.htm>. Acesso em: mar. 2012.
} 
de alavancar a economia capixaba, em um período de ditadura militar, onde as manifestações eram fortemente reprimidas.

Esta conjuntura impediu que os problemas decorrentes do modelo industrial implantado - dependente da ocupação de extensas áreas com o monocultivo de eucalipto - fosse contestado pela sociedade de forma mais incisiva, a exemplo das manifestações contra o setor de papel e celulose que observamos na atualidade, o que facilitou a expansão das atividades da empresa. Ademais, no projeto para esta indústria, assim como nos outros projetos elaborados pelos formuladores da política desenvolvimentista para o Estado, não havia grande preocupação com seus possíveis impactos ambientais (MOREIRA, 1992).

Contudo, Moreira (1992) assinala que, como qualquer grande projeto industrial, a implantação da Aracruz Celulose S/A. interferiu diretamente na organização da vida da população residente em diversas áreas do Espírito Santo, bem como no ambiente local. É por isso que a ação do setor de papel e celulose neste Estado, antes representada pela Aracruz Celulose S/A. e hoje pela Fibria Celulose S/A., é acompanhada por diversos conflitos e manifestações de lideranças comunitárias e sindicais, movimentos sociais, ONGs, etc. Comumente, estas instituições apontam este setor como responsável por causar inúmeros problemas sociais e ambientais desde que foi introduzido no Estado, como, por exemplo, a expulsão de agricultores de base familiar, grupos indígenas e quilombolas de suas terras; alterações no emprego rural; devastação da Mata Atlântica; contaminação das águas por agrotóxicos, homogeneização da paisagem, desertificação dos solos, diminuição da biodiversidade; esgotamento dos recursos hídricos (impacto sobre a umidade do solo, os aquíferos e lençóis freáticos), dentre outros (LOUREIRO, 2006).

Por isso, inúmeros são os estudos que analisam conflitos entre a indústria de papel e celulose e segmentos sociais como indígenas e quilombolas, ou os impactos ambientais causados pelo cultivo de eucalipto promovido pelo setor. Somando-se a estes estudos, entretanto, a partir de um caminho um pouco diverso, o que procuro aqui é analisar como os agricultores de base familiar capixabas, ligados ao setor de papel e celulose por meio do fomento florestal, percebem as alterações no ambiente local causadas por esse setor, não em virtude diretamente das atividades industriais, mas pelo mesmo ser responsável por incentivar e organizar a disseminação do eucalipto na área em que vivem e trabalham.

Assim, antes de ter o objetivo de estabelecer os impactos ao ambiente rural que porventura são causados pelo fomento florestal, a reflexão se concentrará aqui nas percepções que tais agricultores têm a respeito das consequências ambientais provenientes da disseminação do plantio de eucalipto, nas pequenas propriedades espalhadas pelo município de Domingos Martins, localizado na região Centro-Serrana do Espírito Santo. Desta forma, apresentaremos alguns dos principais impactos causados pelo cultivo de eucalipto levantados tanto pela sociedade civil como pela academia, de modo a observar se os mesmos coincidem, se aproximam ou não das percepções dos agricultores a este respeito.

Um dos problemas mais recorrentes creditado ao plantio de eucalipto diz respeito aos seus impactos hidrológicos. Aliás, este é um dos pontos mais polêmicos levantados nos debates sobre os prejuízos ao meio ambiente provocados pelo cultivo por aqueles que se colocam contra a atividade. Em relação a este debate, Lima (2007) apresenta um trabalho de Whitehead e Beadle (2004), autores que analisaram aspectos que devem ser levados em conta para a compreensão do sistema de consumo de água do eucalipto quando comparado nesse quesito com outras plantas. Dentre estes aspectos encontram-se taxas de transpiração, índice de área foliar, eficiência de uso da água, perdas por interceptação e balanço hídrico. Assim, uma das principais conclusões destes autores é a de que o eucalipto não consome mais água por unidade de biomassa produzida do que diversas espécies vegetais.

Vital (2007) defende que os impactos causados pelo cultivo de eucalipto em lençóis freáticos, pequenos cursos d'água ou bacias hidrográficas dependem da região em que se insere a plantação. Para ele, tais problemas ocorrem apenas quando a planta é introduzida em regiões de pouca chuva. Além disso, segundo o autor, estes impactos dependem também da distância entre as plantações e a bacia hidrográfica e da profundidade do lençol freático.

Em um polo oposto, Viana (2004) apresenta um relato do pesquisador sul-africano Harald Witt, extraído 
do painel "O Eucalipto e a Água: Verdade ou Falácia?", que integrou o Seminário Internacional sobre Eucalipto e seus Impactos, realizado no ano de 2001 pela Comissão de Agricultura e Meio Ambiente da Assembleia Legislativa do Estado do Espírito Santo. Neste evento, o palestrante afirma que na África do Sul já existe um consenso de que os cultivos de árvores como pinus e eucalipto interferem na disponibilidade de água daquele país, sendo a questão definir a intensidade dessa interferência e os meios para impedi-la. Ainda segundo o depoimento deste palestrante, apresentado por Viana (2004), na África do Sul, diante dos prejuízos aos recursos hídricos e devido ao enorme consumo de água desta atividade, o país estava discutindo, naquele momento, uma forma de cobrar dos proprietários de grandes plantações de pinus e eucalipto um imposto.

E os agricultores de base familiar de Domingos Martins, o que pensam a este respeito, uma vez que este município é conhecido pela sua vasta disponibilidade de água, além de cachoeiras, nascentes e córregos, que cortam vários estabelecimentos rurais? Ao perguntarmos ao agricultor C.B., ex-integrado, se o mesmo acreditava que, porventura, o cultivo de eucalipto poderia causar algum dano ao ambiente, imediatamente o mesmo respondeu que sim e sua primeira observação a este respeito estava relacionada, justamente, ao consumo de água que o plantio de eucalipto demanda. Vejamos alguns trechos do relato do entrevistado:

Ele [o eucalipto] é um espalhador de chuva e um chupador de água. Eu acho que ele prejudica muito o meio ambiente. Ele tira a chuva, e a chuva que cai dentro dele não vai para o córrego, hoje você entra lá no meio do eucalipto e vê que tá sequíssimo, e se você entrar numa mata daqui você vê como tá molhado (C.B., agricultor ex-integrado).

O interessante é observar que para organizar sua percepção, da mesma forma que os pesquisadores citados por Viana (2004) fazem, porém, por meio de sua experiência cotidiana no trabalho na terra, este agricultor traça uma comparação entre os solos da região ocupados pelo eucalipto e aqueles ocupados pela floresta nativa. E, como vimos, para ele basta apenas confrontarmos a umidade do solo de cada uma das duas áreas para percebermos como o eucalipto consome água de forma mais intensa que as demais vegetações presentes naquela região.

Ainda neste sentido, Vital (2007) observa que em períodos de estiagem é possível perceber que a quantidade de água presente nos solos cultivados com eucalipto é menor que nos solos ocupados com florestas de mata atlântica. Isto ocorre, segundo o autor, porque as árvores presentes nas florestas de mata atlântica têm raízes longas, que chegam a atingir a profundidade de 5 metros, ao passo que as raízes do eucalipto não passam de 2,5 metros, ou seja, possuem no máximo a metade do tamanho das raízes das árvores características da mata atlântica. Então, a mata atlântica, por buscar água em profundidades maiores que o eucalipto, produz um menor ressecamento no solo.

Na percepção do ex-integrado C. B., o eucalipto também é responsável por diminuir a disponibilidade de água das nascentes daquela localidade: "Então essas nascentes e águas que nós temos hoje tá enfraquecendo demais da conta". Aliás, preocupação com as nascentes foi tema recorrente nos depoimentos dos agricultores, como podemos perceber nas falas a seguir: "Eu não sei não, mas planta eucalipto perto das águas pra você ver." (E.H., agricultor não integrado). "Com certeza, é a respeito da água, a água vai acabar por causa do eucalipto. [...] Isso aí [o eucalipto] tá comendo a água todinha, depois não tem como voltar a água mais". (O.K., agricultor não integrado). Ainda em relação a esta preocupação, segue abaixo o relato de dois agricultores a respeito dos impactos aos recursos hídricos que em suas opiniões podem ser atribuídos às plantações de eucalipto:

Lá na região tinha uma família que passou toda a vida ali, aí os filhos foram vendendo a terra, aí hoje eles ficaram num lugarzinho lá e nem têm mais água pra beber, vive ali quase sem água, acabou a água na propriedade, e nós vimos que lá existia mesmo muita água, eles plantavam e irrigavam, sobrava água (C.B., agricultor ex-integrado).

Agora, realmente eu não sou a favor de plantar numa área próxima à nascente, uma área que você possa plantar outras culturas. É uma cultura que cresce muito rápido, então é claro que ela precisa de mais nutrientes do que outra cultura qualquer. Só pelo crescimento a gente percebe (M.S., agricultora integrada). 
Além de relacionar o cultivo do eucalipto com a diminuição da disponibilidade de água de nascentes e córregos que atravessam as propriedades da região, muitos dos agricultores entrevistados associaram a diminuição e irregularidade da distribuição de chuvas na localidade à expansão do cultivo de eucalipto a partir de meados dos anos 1990:

Teve uma mudança porque bem mais antigo a gente tinha a previsão que em setembro você podia plantar as roças todinhas, porque quando chegava setembro não falhava a chuva. Hoje não, o pessoal ficou esperando aí e a chuva não chegou. A gente plantou um pouco de milho lá, mas hoje ainda tava seco, não tá germinando bem. Eu não sei se foi impacto do eucalipto ou o que deu esse impacto, porque, não sei se você tem observado esse mapa que eles fazem por satélite, nessa área de Domingos Martins a mata e o eucalipto estão a 50\% cada um (E.B., agricultor integrado).

Do mesmo modo, M.B., agricultor ex-integrado, também considera que a alteração na distribuição das chuvas na localidade pode ser resultado da disseminação do cultivo de eucalipto:

Antes parece que chovia mais, agora chove muito pouco. Tem gente que fala que é por causa do eucalipto, ele parece que solta alguma coisa que não deixa chover, eu não sei. Muita gente fala que sim (M.B., agricultor ex-integrado).

Além da interferência na distribuição das chuvas e da destruição de nascentes, alguns agricultores entrevistados associaram o assoreamento de rios e, por conseguinte, a ocorrência de enchentes e alagamentos na região, à expansão do cultivo de eucalipto por meio do fomento florestal. A este respeito, a agricultora integrada M.S., ao ser indagada se achava que os plantios de eucalipto causavam algum impacto ao ambiente local, sua resposta foi a seguinte: "A água secou, dá muita enxurrada." De forma parecida com esta agricultora, o agricultor ex-integrado C.B. faz a seguinte colocação, em virtude da construção das estradas exigidas para 0 escoamento da madeira produzida:
Em compensação acontece problema por causa da estrada também, tá dando muita enchente nos rios. Há cinco anos atrás não tinha estrada pra tudo quanto é ponta de morro, a estrada bate lá naqueles pontões de morro que em menos de meia hora está dentro do rio, em menos de uma hora o rio tá alto. Porque se chovesse e não tivesse estrada nem o eucalipto, ia chover e ficar parado lá, daqui não sei quantos anos o rio ia ficar sempre naquele estado, não ia subir de vez nem abaixar mais. Quando o rio sobe um dia ou dois dias ele abaixa de novo. Esse pouquinho de chuva que dá aí o eucalipto não deixa chegar no rio (C.B., agricultor ex-integrado).

Diante dos relatos, é possível perceber que, apesar de parte da literatura a respeito dos impactos ao ambiente causados pelo cultivo de eucalipto afirmar que este não promove mais problemas aos recursos hídricos que outras plantas e/ou atividades agrícolas, na percepção dos agricultores tais impactos acontecem sim, e com muita frequência. Neste sentido, Lima (2007) assevera que essas posições controversas revelam a necessidade de avaliar de uma forma diferente a relação entre o cultivo de eucalipto e a água. Deste modo, este autor ressalta que uma análise de laboratório, restringida à comparação entre o consumo de água entre diversas plantas, dentre elas o eucalipto, é algo insuficiente para descaracterizar os impactos causados pelo plantio de árvores para a indústria. Portanto, torna-se fundamental considerar outros aspectos. Conforme o autor:

Em outras palavras, a questão fundamental a ser abordada na relação entre florestas plantadas e a água deve envolver sim o consumo da água, mas deve, com certeza, incluir muitas outras considerações tais como a qualidade da água, a sedimentação, a qualidade do ecossistema aquático, a hidrologia da microbacia, a permanência dos fluxos de base, o controle dos picos de vazão, assim como o princípio fundamental de equidade ao acesso à água (LIMA, 2007, p. 2).

Assim, para Lima (2007), as observações dos agricultores em relação aos impactos ambientais causados pelo eucalipto, discutidas anteriormente, não estão ligadas apenas à quantidade de água consumida pelo cultivo, mas podem ser associadas diretamente ao modo como o manejo do cultivo de eucalipto tem utilizado os recursos hídricos 
disponíveis, bem como às consequências desse manejo para a qualidade da água, recurso primordial para a agricultura.

Se há controvérsias em relação a determinados impactos ambientais do monocultivo de eucalipto, a exemplo dos impactos hidrológicos, quando o impacto tratado é a diminuição da biodiversidade decorrente dessa atividade, parece que há um consenso. Assim, aqueles que se colocam a favor desta atividade tendem, em seus trabalhos, a atenuar tal problema, apesar de reconhecê-lo. Por outro lado, os setores que se colocam contra os extensos plantios da espécie destacam como a atividade tem impactado a biodiversidade em diversas regiões. Esta questão torna-se interessante de ser observada na área que se configurou como local de pesquisa para este trabalho, na medida em que, como já destacamos em outros momentos, a mesma comporta uma das maiores reservas de Mata Atlântica do Espírito Santo.

Ao abordar a relação entre o monocultivo de eucalipto e a biodiversidade, Vital (2007) faz uma ponderação e afirma que estes impactos irão depender do bioma e da condição prévia da região onde o plantio for introduzido. Deste modo, para ele, se as plantações forem introduzidas em regiões de floresta nativa, o resultado será a diminuição da biodiversidade, situação que "pode ocorrer por causa de sombras, competição por água e nutrientes, perturbações no solo, efeitos alelopáticos (efeitos de substâncias químicas do eucalipto sobre outras formas de vegetação) ou efeitos cumulativos sobre o solo" (VITAL, 2007, p. 256). Contudo, segundo o autor, se as plantações de eucalipto forem introduzidas em áreas de savana ou em regiões desmatadas, podem promover aumento da biodiversidade.

Para Viana (2004), a ausência ou a diminuta biodiversidade em plantações de eucalipto é a crítica mais inconteste acerca dos efeitos danosos ao meio ambiente promovidos por esta atividade. Além disso, o autor acrescenta que é indubitável o fato de que qualquer monocultura é incapaz de conter uma grande diversidade de fauna, já que não dispõe de nichos apropriados para as diversas formas de vida. Outra hipótese que o autor afirma importante ser levantada é a de que a ausência de água e o fato da folha de eucalipto ser indigesta para os animais contribuam para a baixa diversidade de espécies no interior destas árvores. Vital (2007) acrescenta que em plantações de eucalipto extensas, como as comerciais, mesmo que apresentem outras espécies de árvores, poucas espécies de aves se adaptarão àquele espaço, dada a pouca disponibilidade de alimentos, por exemplo. Soma-se a isso o fato de o eucalipto comercial ser cortado no máximo em sete anos, o que impede a criação de habitats para a vida silvestre, já que a maximização da produção é o objetivo da empresa.

Ao abordar os impactos ambientais do eucalipto, os agricultores de Domingos Martins também percebem alterações na biodiversidade da região. Assim, foi muito comum entre os depoimentos dos mesmos a advertência de que nas plantações de eucalipto há, por exemplo, pouca ou nenhuma espécie de animal, conforme o trecho abaixo extraído de uma das entrevistas:

\begin{abstract}
[...] Se você pegar uma área, cercar ela e deixar reflorestar, você não vai mexer nela. Aquilo ali vai criar capim e tudo. Mas o que adianta reflorestar com eucalipto se dentro de 7 anos você vai lá e corta tudo? Eu não sei não, mas planta eucalipto perto das águas pra você ver. [...]. $\mathrm{O}$ meio ambiente com isso aí tá pior porque onde tem eucalipto é preferível ter pasto, porque pelo menos ali tem uma vida andando, e no eucalipto nem passarinho vai (E.H., agricultor não integrado).
\end{abstract}

É interessante perceber que, assim como os estudiosos levantaram, E.H., um agricultor não integrado, entende que, dentre outros fatores, não é possível estabelecer uma biodiversidade entre as plantações de eucalipto, já que depois de sete anos as árvores são cortadas. Assim como o relato apresentado, há outros relatos semelhantes, em que os agricultores expõem suas preocupações a respeito dos impactos à fauna e flora causados pela disseminação do cultivo de eucalipto em larga escala: "você vê que onde tem eucalipto não tem um passarinho dentro, não tem nada, só tem aquelas terras limpas debaixo. Não dá fruta, não dá nada" (O. $\mathrm{K}$., agricultor não integrado).
E sem falar que dentro do eucalipto não tem vida, você não vê bicho no meio do eucalipto, não tem passarinho, não vê nada [...]. A gente não vê nenhum tipo de bicho, por exemplo, onde tem, aparece tatu, essas coisas, mas é porque tem uma mata na beira, agora onde tem só eu- calipto você não vê nada (F.L., agricultor não integrado). 
Além destes impactos, vimos nas reflexões anteriores de Vital (2007) que o eucalipto pode ter implicações alelopáticas. Isto significa que a planta pode exalar substâncias químicas que podem causar efeitos a outras formas de vegetação, criando, por exemplo, no solo onde está inserida, condições desfavoráveis ao crescimento de outras plantas ao seu redor. Segundo Viana (2004), esta situação, em longo prazo, poderia culminar no desaparecimento do ecossistema original. Assim como estes autores, no entanto, sem dominar o termo técnico desse possível efeito do eucalipto, os agricultores apontam em seu relatos que desconfiam que a planta pode emitir alguma substância prejudicial aos demais seres vivos:

E sem falar que dentro do eucalipto não tem vida, você não vê bicho no meio do eucalipto, não tem passarinho, não vê nada, inclusive, eu não tenho dados que comprovem isso, mas eu acho que só do fato da gente trabalhar no meio do eucalipto, ele libera alguma toxina que faz mal pra gente porque, um exemplo, no meio do eucalipto você não vê nenhum passarinho fazendo ninho num pé de eucalipto, você não vê outros bichos, acredito eu que ele solte alguma toxina que nada de botar um ovo, um passarinho chocar e nascer, acredito eu que há um impacto físico na gente também, a gente fica no meio do eucalipto, deve fazer alguma alteração no nosso organismo (F.L., agricultor não integrado).

Além disso, a gente nota que a propriedade que tem em volta dela, eucalipto, até pra você criar uma criação fica mais difícil. Depois que nasceu eucalipto em volta da minha propriedade aqui, eu já perdi umas 8 cabeças de criação. Eles morrem, secam (M. F., agricultor não integrado).

A partir das reflexões desenvolvidas acima, observamos que, apesar de, obviamente, não fazerem uso dos termos técnicos e científicos para se referirem aos impactos ao ambiente causados pelo cultivo de eucalipto, os agricultores integrados e não integrados ao setor fabricante de celulose, que vivem e trabalham em uma região em que o cultivo de eucalipto encontra-se disseminado, associam diversas alterações ambientais naquele local ao cultivo. Problemas estes que coincidem com afirmações, ainda que às vezes vagas, de pesquisas científicas a respeito do tema. Deste modo, se a experiência e a percepção dos agricultores, tanto integrados quanto não integrados, apontam problemas, junto com tais indicações emerge a necessidade do estabelecimento de pesquisas que levem em conta tais percepções, pois um caminho para descortinar certas controvérsias que envolvem a definição dos reais impactos do monocultivo de eucalipto pode ser por intermédio daqueles que vivenciam os impactos no seu cotidiano.

\section{Considerações finais}

Com este trabalho, procuramos fazer examinar as alterações ambientais causadas pela disseminação do monocultivo de eucalipto por outro ângulo, qual seja, por meio de uma reflexão sobre a percepção, a este respeito, dos agricultores familiares de uma região em que o fomento florestal, um tipo de integração entre agricultores e indústria, está consolidado. Assim, antes de definir ou estabelecer tais impactos, o que motivou este artigo foi a análise de como os agricultores percebem e/ou constatam os feitos desse cultivo, já que lidam diretamente com a atividade. Aqueles que não lidam, são vizinhos, amigos, já trabalharam no plantio ou conhecem agricultores que fazem este tipo de plantio.

Diante disso, tornou-se interessante observar até que ponto as percepções destes agricultores se aproximam ou não das constatações presentes na literatura científica sobre o tema. De tal modo que foi possível perceber que, mesmo não se valendo de termos técnicos para explicar o que tem ocorrido na região de Domingos Martins, após a disseminação do cultivo de eucalipto - que teve início a partir de meados dos anos 1990, por meio do programa de fomento florestal difundido, inicialmente, pela Aracruz Celulose S/A. e, atualmente, mantido pela Fibria Celulose S/A. - tais agricultores identificaram problemas muito próximos aos estabelecidos pela literatura corrente. Até mesmo em se tratando de um impacto ainda nebuloso para os pesquisadores, como os efeitos alelopáticos causados pelos plantios de eucalipto.

Ao analisar a literatura sobre o tema, cujo cerne é a apresentação de argumentos favoráveis ao plantio em larga escala de eucalipto para fins industriais, observa- 
mos que há uma disposição à minimização dos impactos ambientais causados pela atividade, ou mesmo uma tendência a colocar em dúvida tais impactos, categorizados muitas vezes com a palavra "controverso". Contudo, se alguns dos impactos ambientais apontados pela literatura corrente ainda são tachados de controversos - a exemplo do consumo de água exigido pelo monocultivo de euca-

\section{Referências}

ACSELRAD, Henri. O movimento de resistência à monocultura do eucalipto no Norte do Espírito Santo e Extremo Sul da Bahia - uma sociologia da recusa e do consentimento em contexto de conflito ambiental. In: CONGRESSO BRASILEIRO DE SOCIOLOGIA, 13. Recife, 29 de maio a $1^{\circ}$ de junho de 2007. Anais.

ALBERGARIA, Alessandra Vasconcelos; LORETO, Maria das Dores Saraiva de. Políticas públicas como estratégia para o desenvolvimento Rural. In: CONGRESSO LATINO-AMERICANO DE SOCIOLOGIA RURAL, 8., Porto de Galinhas, 2010. Anais. Disponível em: <http://baseportal.com/cgi-in/ baseportal.pl?htx=/HdeBarros/ALASRU2010/2010trabs\&lo calparams $=1 \& \mathrm{db}=2010$ trabs $\& \mathrm{cmd}=$ list $\&$ range $=1560,20 \& \mathrm{c}$ $\mathrm{md}=\mathrm{all} \& \mathrm{Id}=1446>$. Acesso em: fev. 2011.

AMBRÓZIO, Aldo. Analítica das relações de poder inerentes ao processo de reestruturação produtiva da Aracruz Celulose S. A., na década de 1990. 2005. 140 f. Vitória, Dissertação (Mestrado em Administração) - Programa de Pós-Graduação em Administração da Universidade Federal do Espírito Santo, Centro de Ciências Jurídicas e Econômicas, 2005.

ANDRADE, José Célio Silveira; DIAS, Camila Carneiro. Conflito \& cooperação: análise das estratégias socioambientais da Aracruz Celulose S/A. Ilhéus-BA: Editus, 2003.

ANTOGIOVANNI, Lídia Lúcia. Território como abrigo e território como recurso: territorialidades em tensão e projetos insurgentes no Norte do Espírito Santo. Niterói, Dissertação (Mestrado) - Pós-Graduação em Geografia, Universidade Federal Fluminense, 2006.

ARACRUZ Celulose S/A. Revista do Programa de Fomento Florestal da Aracruz Celulose, ano I, n. 1, ago. 2003.

. Revista Produtor Florestal, n. 4, julho de 2004.

. Programa Produtor Florestal. Espírito Santo, 2007. lipto -, para os agricultores, tanto os integrados como os não integrados ao setor de papel e celulose, estes efeitos são bem claros. Neste sentido, para que seja possível descortinar os reais impactos causados pela atividade, um caminho possível seria o de atrelar as pesquisas de laboratório sobre o tema aos indícios apontados por aqueles que vivenciam tais impactos rotineiramente.

BONI, Valdete; QUARESMA, Sílvia Jurema. Aprendendo a entrevistar: como fazer entrevistas em Ciências Sociais. Rev. Elet. dos Pós-Graduandos em Sociologia Política da UFSC,v. 2, n. 1,p. 68-80, jan./jul. 2005.

CANTO, Juliana Lorensi et al. Aspectos sociais do fomento florestal no Estado do Espírito Santo. Revista Cerne, Lavras, v. 15, n. 2, p. 123-132, abr./jun. 2009. Disponível em: <http:// www.dcf.ufla.br/cerne/artigos/08-01-20102781v15_n2_artigo\%2001.pdf>. Acesso em: dez. 2012.

DAL'COL, Jairo. Fomento florestal: uma oportunidade de negócio. Rev. Opiniões, jun.-ago. 2006. Disponível em: $<$ http:// www.revistaopinioes.com.br/cp/materia.php?id=390>. Acesso em: ago. 2010.

DALCOMUNI, Sonia Maria. A implantação da Aracruz Celulose no Espírito Santo - principais interesses em jogo. Rio de Janeiro, Dissertação (Mestrado em Desenvolvimento Agrícola) - Programa de Pós-Graduação em Desenvolvimento Agrícola, Universidade Federal Rural do Rio de Janeiro, 1990.

DE'NADAI, Alcir; OVERBEEK, Winfridus; SOARES, Luiz Alberto. Plantações de eucalipto e produção de celulose: promessas de emprego e destruição de trabalho. O caso Aracruz Celulose no Brasil. Movimento Mundial pelas Florestas Tropicais, Brasil, 2005.

DUARTE, Rosália. Pesquisa qualitativa: reflexões sobre o trabalho de campo. Cadernos de Pesquisa, n. 115, p. 139-154, mar. 2002.

ECOTEC. Economia e Engenharia Industrial. S.A. Potencial florestal e silvicultura no Estado do Espírito Santo. In: Estudos para o desenvolvimento do Estado do Espírito Santo, v. 3, 1967.

FASE. Federação de Órgãos para Assistência Social e Educacional. Violação de direitos econômicos, sociais, culturais e ambientais na monocultura do eucalipto: a Aracruz Celulose 
e o Estado do Espírito Santo-Brasil. Vitória, 13 de agosto de 2002. Disponível em: <www.fase.org.br/v2/admin/anexos/ acervo/10 relatoriodesc.pdf $>$. Acesso em: jun. 2012.

FERREIRA, Simone Raquel Batista. Da fartura à escassez - a agroindústria de celulose e o fim de territórios comunais no Extremo Norte do Espírito Santo. 167 f. São Paulo, Dissertação (Mestrado em Geografia Humana) - Faculdade de Filosofia, Letras e Ciências Humanas - Departamento de Geografia, Universidade de São Paulo, 2002.

FIBRIA Celulose S/A. Plano de Manejo Unidade Aracruz Regiões do Espirito Santo e Bahia. Maio/2010. Disponível em: <www.fibria.com.br/.../plano_de_manejo_fibria_es_ba_2010. pdf $>$. Acesso em: out. 2010.

FOOD AND AGRICULTURE ORGANIZATION OF THE UNITED NATIONS (FAO). Incentivos e mecanismos financeiros para o manejo florestal sustentável na região Sul do Brasil. Curitiba, fev. 2004. Disponível em <www.fao.org/ forestry/12000-09ec4e1c04ebfcd232f76c89136cadcf.pdf>. Acesso em: dez. 2010.

GALVÊAS, Pedro Arlindo Oliveira; DADALTO, Gilmar Gusmão (Coord.). Novo PEDEAG 2007-2025: Plano Estratégico de Desenvolvimento da Agricultura Capixaba. Estudo Setorial Silvicultura. Vitória-ES, out. 2007. Disponível em: $<$ http:// www.seag.es.gov.br/pedeag/pdf/silvicultura.pdf $>$. Acesso em: 08/07/2008.

GOMES, Ana Paula Wendling; GOMES, Adriano Provezando. Sistema de integração na avicultura de corte: um estudo de caso na região de Viçosa-MG. In: ENCONTRO DA SOCIEDADE BRASILEIRA DE ECONOMIA, ADMINISTRAÇÃO E SOCIOLOGIA RURAL, 46., Rio Branco - Acre, 20 a 23 de julho de 2008. Anais.

GONÇALVES, Múcio Tosta. A formação da economia das plantações florestais nos Vales do Rio Doce e do Aço de Minas Gerais (1940-2000): notas sobre história econômica e ambiental de uma região. In: SEMINÁRIO SOBRE A ECONOMIA MINEIRA, 2006, Diamantina. Anais.

HASSE, Geraldo. Eucalipto: histórias de um imigrante vegetal. Porto Alegre: Já Editores, 2006.

IJSN - INSTITUTO JONES DOS SANTOS NEVES. Perfil Regional Região Sudoeste Serrana. Microrregião Administrativa 4. Vitória, ES, 2009.

KENGEN, Sebastião. Estudo de caso de integração vertical: Programa de Fomento Florestal da Aracruz Celulose S/A. Brasil. Documento elaborado para o Banco Interamericano de
Desenvolvimento. Instrumentos Institucionais para o Desenvolvimento dos Proprietários de Pequenas Terras com Vocação Florestal. Rio Grande do Sul, 2002.

LIMA, Walter de Paula. Impacto ambiental das florestas plantadas. In: CONGRESSO INTERNACIONAL DE AGROENERGIA E BIOCOMBUSTÍVEIS, 2007. Anais. Disponível em: <http://www.cpamn.embrapa.br/agrobioenergia/palestras/ IMPACTO\%20AMBIENTAL\%20DAS\%20FLORESTAS\%20 PLANTADAS\%20.PDF>. Acesso em: 08/03/2012.

LOUREIRO, Klítia. O processo de modernização autoritária da agricultura no Espírito Santo: os índios Tupiniquim e Guarani Mbya e a empresa Aracruz Celulose. Vitória, Dissertação (Mestrado em História) - Programa de Pós-Graduação em História, Universidade Federal do Espírito Santo, 2006.

MENEZES, Marilda Aparecida. Redes e enredos nas trilhas dos migrantes: um estudo de famílias de camponeses-migrantes. Rio de Janeiro: Relume Dumará; João Pessoa: Ed. UFPB, 2002.

MOREIRA, Terezinha. Aracruz Celulose S.A: investimento social e lógico empresarial. Rio de Janeiro: UFRJ/Instituto de Economia Industrial, 1992.

MINAYO, Maria Cecília de Souza (Org.). Pesquisa social: teoria, método e criatividade. 6.ed. Petrópolis: Vozes, 1996.

NADER, Maria Beatriz. Industrialização, aumento populacional e a diversificação do mercado de trabalho: Vitória em dados. 1970-2000. Rev. História Hoje, Associação Nacional de História, n. 12, v. 4, abr. 2007. Disponível em: <http:// www.anpuh.org/revistahistoria/view?ID_REVISTA_HISTORIA=12>. Acesso em: 12/07/2008.

NÓBREGA, Neri Ellen Fernandes da et al. Classificação climática e balanço hídrico climatológico para a região produtora de morango em Domingos Martins - ES. In: CONGRESSO BRASILEIRO DE FRUTICULTURA, 20.,Vitória-ES, 2008. Anais.

PAULILO, Maria Ignês. Produtor e agroindústria: consensos e dissensos. O caso de Santa Catarina. Florianópolis: Coedição Secretaria de Estado da Cultura e do Esporte e Editora da UFSC, 1990.

PAYÉS, M. A. M. O empresário familiar rural: integração à agroindústria de fumo e diferenciação. Campinas, Tese (Doutorado) - Instituto de Economia da UNICAMP, 1993.

PICOLOTTO, Everton Lazzaretti. As mãos que alimentam a nação: agricultura familiar, sindicalismo e política. Rio de Janeiro, Tese (Mestrado em Ciências Sociais em Desenvolvi- 
mento, Agricultura e Sociedade) - Programa de Pós-Graduação em Ciências Sociais em Desenvolvimento, Agricultura e Sociedade, Universidade Federal Rural do Rio de Janeiro, 2011.

PIÑEIRO, Martins; LLOVET, Ignacio. Introducción. In: Cambio técnico en el agro latinoamericano; situación y perspectivas en la década de 1980. IICA, Serie Investigación y Desarrollo, San José, Costa Rica: IICA, n. 10, 1985.

PRYOR, Lindsay D. Aspectos da cultura do eucalipto no Brasil. Revista Scientia Forestalis, n. 2/3, p. 53-59, 1971. Disponível em: <http://www.ipef.br>. Acesso em: 15/03/2012.

SCHNEIDER, Sérgio. Turismo em comunidades rurais: inclusão social por meio de atividades não agrícolas. In: BRASIL, Ministério do Turismo. (Org.). Turismo social: diálogos do turismo - uma viagem de inclusão. v. 1. Rio de Janeiro: Ministério do Turismo/Instituto Brasileiro de Administração Municipal-IBAM, 2006.

SOARES, Naisy Silva; OLIVEIRA Roldão José de; CARVALHO, Kaio Henrique Adame de; SILVA, Márcio Lopes da; JACOVINE, Laércio Antônio Gonçalves; VALVERDE; Sebastião Renato. A cadeia produtiva da celulose e do papel no Brasil. Rev. Floresta, Curitiba, v. 40, n. 1, p. 1-22, jan./mar. 2010.

SOCIEDADE Brasileira de Silvicultura. Fatos e números do Brasil florestal. Nov. 2006. Disponível em: <http://www. ipef.br/estatisticas/relatorios/SBS-2005.pdf>. Acesso em: 08/07/2008.
TERRA; Vilma R. et al. Estudo limnológico visando à avaliação da qualidade das águas do rio Jucu Braço Norte, ES. Rev. Natureza on-line, Santa Teresa-ES, n. 8, p. 8-13, 2010. Disponível em: <www.naturezaonline.com.br/natureza/conteudo/.../02_TerraVRetal_0813.pdf >. Acesso em: fev. 2011.

VIANA, Maurício Boratto. O eucalipto e os efeitos ambientais do seu plantio em escala. Câmara dos Deputados, 2004. Disponível em: $<$ http://bd.camara.gov.br/bd/bitstream/handle/ bdcamara/1162/eucalipto_efeitos_boratto.pdf $>$. Acesso em: 10/03/2012.

VINHA, Valeria Gonçalves da. O Estado e as empresas “ecologicamente comprometidas" sob a ótica do neocorporativismo e do State-Society Synergy approach: o caso do setor de papel e celulose. Revista Arché Interdisciplinar, ano VIII, n. 25, 1999.

VITAL, Marcos H. F. Impacto ambiental de florestas de eucalipto. Revista do BNDES, Rio de Janeiro, v. 14, n. 28, p. 235-276, dez. 2007.

YACCOUB, Hilaine. A monocultura, a Aracruz Celulose e os quilombolas do Espírito Santo. Observatório de Políticas Públicas Ambientais da América Latina e Caribe. Out. 2005. Disponível em: $<$ www.opalc.org.br/index2.php?option=com content\&do_pdf=1\&id=4>. Acesso em: 03/05/2008.

ZIEBERT, R. A.; SHIKIDA, P. F. A. Avicultura e produção integrada em Santa Helena, Estado do Paraná: uma abordagem a partir da nova economia institucional. Rev. Agricultura, São Paulo, v. 51, n. 1, p. 71-86, jan./jun. 2004.

Recebido em 15 de janeiro de 2013. Aceito em 27 de setembro de 2013. Publicado em dezembro de 2013. 